\title{
Spinning of a gigantic bundle of hollow fibrils by a spirally moving higher plant protoplast
}

\author{
Tomoko Seyama $\cdot$ Satoshi Kimura $\cdot$ \\ Hamako Sasamoto $\cdot$ Hisashi Abe $\cdot$ Tetsuo Kondo
}

Published online: 21 June 2008

(C) Springer-Verlag 2008

\section{Editorial note to: Planta (2008) 227:1187-1197}

\section{DOI 10.1007/s00425-008-0689-1}

Upon publication of the above-mentioned paper, we regretfully became aware that Professor Hamako Sasamoto, who is listed as one of the coauthors of this work, was not afforded the required opportunity to know about this manu- script, or to comment about its content. This omission constitutes unauthorized and inappropriate use of Professor Sasamoto's name and is a clear violation of Planta's express instruction to corresponding authors that "Submission of a manuscript implies that its publication has been approved by all coauthors."

The online version of the original article can be found under doi: 10.1007/s00425-008-0689-1.

T. Seyama $\cdot$ T. Kondo $(\bowtie)$

Bio-Architecture Center (KBAC) and Graduate School

of Bioresource and Bioenvironmental Sciences,

Kyushu University, 6-10-1 Hakozaki, Higashi-ku,

Fukuoka 812-8581, Japan

e-mail: tekondo@agr.kyushu-u.ac.jp

S. Kimura

Graduate School of Agricultural and Life Sciences,

The University of Tokyo, 1-1-1 Yayoi, Bunkyo-ku,

Tokyo 113-8657, Japan

H. Sasamoto $\cdot$ H. Abe

Forestry and Forest Products Research Institute (FFPRI),

1 Matsunosato, Tsukuba, Ibaraki 305-8687, Japan 